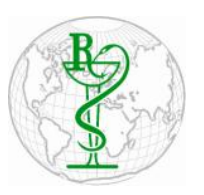

INDO GLOBAL JOURNAL OF

PHARMACEUTICAL SCIENCES

ISSN 2249- 1023

\title{
Production of Serine Protease Inhibitors from Momordica Dioica Cell Cultures
}

\author{
Avneesh Kumar ${ }^{1}$, Surbhi Lodha ${ }^{2}$, Pallavi Dwiwedi ${ }^{* 2}$ \\ ${ }^{I}$ Faculty of Agricultural and Nutritional Sciences, Christian-Albrechts- University of Kiel, Olshausenstr 40, D-24118 Kiel, Germany \\ ${ }^{2}$ Department of Biotechnology, Sir Padampat Singhania University, Udaipur-313001, Rajasthan, India
}

\begin{abstract}
Address for Correspondance Pallavi Dwiwedi, pallavi.dwivedi@ spsu.ac.in

Keywords Callus

Cultures;

Momordica

dioica; Serine

Protease

Inhibitors;

Bioinsecticides.

ABSTRACT: Protein molecules which bind and inhibit the activity of serine protease enzymes are known as serine protease inhibitors. These are proteolytic enzymes which possess triad of aspartic acid, histidine and serine in their active site. They have been found in microbes, plant tissues, animal tissues and fluids and insects. In plants, they play a vital role in defence mechanism against predators and pathogens. Serine protease inhibitors are mostly detected in seed extracts. The present study aims the development of callus cultures of Momordica dioica for the production of serine protease inhibitors which may have potential as bioinsecticide. Callus cultures of $M$. dioica were established from various explants which obtained from in-vitro as well as invivo growing plants. $M$. dioica seedlings were developed under in-vitro condition through germination of stored seeds on water agar medium. Sixty percent germination was achieved. Leaves obtained from outdoor grown plants were proved to be the best explants for callus formation with $60 \%$ rate of callus induction. Protein profile of callus and media samples was analyzed through SDS-PAGE and two proteins were found to be similar and expressed in seeds also along with several others. Trypsin inhibitory activity was reported in callus extract (91\%) and media samples (54\%). Since trypsin inhibitory activity was also observed in the protein extracted from the medium, it is believed that the protein involved is extracellular. (C) 2015 iGlobal Research and Publishing Foundation. All rights reserved.
\end{abstract}

NOTE: Full length manuscript of Kumar et al. Production of Serine Protease Inhibitors from Momordica dioica Cell Cultures. 2014; 4(3): 209.

\section{INTRODUCTION}

Serine proteases are proteolytic enzymes which possess triad of aspartic acid, histidine and serine in their active site. These enzymes are widely distributed among living organisms including plants, animals, microbes and insects where they take part in a variety of physiological processes like protein digestion in intestine, blood clotting, muscle contraction etc. Living organisms also contain inhibitory molecules which bind at the active site of serine protease leading to their inactivation when there is no requirement. These inhibitory molecules are named as serine protease inhibitors. Serine protease inhibitors have been found in microbes, animal tissues and fluids, plant tissues and insects. Naturally occurring protease inhibitors are polypeptides and proteins which have been classified into families primarily on the basis of the disulfide bonding pattern and the sequence homology of the reactive site. The reactive site is defined as the portion of the primary sequence that directly interacts with the protease. Most of the inhibitors follow a common mechanism of inhibition where inhibitors mimic the structure of substrate molecule, therefore, bind at the active site of enzyme and prevent its action [1]. Presence of serine protease inhibitors is a more common phenomenon in animal kingdom as compared to plant kingdom. In animals they play a vital role in regulation of variety of physiological processes which are mediated 


\section{Indo Global Journal of Pharmaceutical Sciences, 2015; 5(2): 124-128}

through proteins like blood clotting, inflammation, muscle contraction, movement of blood cells, signal transduction, cell division, digestion etc. In addition to having many natural physiological functions these inhibitory molecules find applications in medicine, agricultural, biology etc. They have been implemented in a number of pathological conditions in humans including pulmonary emphysema, various blood clotting disorders, inflammatory processes etc. In contrast to animals, presence of these inhibitory proteins is limited to few plant families, namely leguminosae, solanaceae and gramineae [2]. In plants, protease inhibitors play a vital role in defense mechanism against predators and pathogens [3]. These inhibitory molecules prevent proteolysis in the midgut of insect larvae leading to their starvation and subsequent death [4]. Serine protease inhibitor was first reported from soybean which was found to be toxic to the larvae of flour beetle, Tribolium confusum [5]. Following these initial studies, many reports have demonstrated retardation in the growth and development of insect pests fed on diets incorporating serine protease inhibitors (SPIs), or on transgenic plants expressing SPIs. Four serine protease inhibitors were identified from Solanum nigrum, which were found to be different substantially in their substrate specificity, accumulation pattern and their effect against different herbivorous insects [6]. Kansal et al. [7] have detected presence of trypsin inhibitor in Cicer arietinum and its efficacy against Helicoverpa armigera. Human elastase inhibitory action of serine protease inhibitor from Tamarindus indica was reported by Fook et al. [8].

A novel serine protease inhibitor was detected in seed extracts of Momordica dioica in our laboratory (unpublished). The plant belongs to family cucurbitaceae and is native of tropical Asia and distributed throughout India. The green fruits and leaves of $M$. dioica are used as vegetables. Decoction of different parts of $M$. dioica have many medicinal uses like antifungal, anti-inflammatory, hepatoprotective, anti-malarial, anti-parasitic, antiseptic, antioxidant, hypoglycemic, antidiabetic, insecticidal, anticancer and analgesic properties [9, 10, \& 11]. Its cultivation can also be done using the tuberous roots and stem cuttings but it is not feasible because of limited availability of tuberous roots and late availability of stem cuttings in fruiting season. In addition, tuberous roots have low multiplication rate [12]. Thus seeds are not available in plenty. Establishment of callus cultures can possibly overcome this problem. However, such cultures should produce the serine protease inhibitors, in appropriate quantity for their commercial utilization.

The present paper describes establishment of callus cultures of $M$. dioica and production of serine protease inhibitor proteins under in-vitro conditions.

\section{MATERIALS \& METHODS}

\section{Callus induction}

Three different types of explants (leaves, hypocotyl segments, cotyledons) were collected from in-vitro raised seedlings of $M$. dioica and used for callus induction. In addition, three more explants (leves, nodal segments, inter nodal segments) were collected and used for callus induction from $M$. dioica plant grown outdoor. Explants from outdoor grown plants were washed with tap water to remove adhering dirt. Surface sterilization was done with $0.2 \% \mathrm{HgCl}_{2}$ solution containing few drops of Tween-80 for ten minutes. Sterilents were removed by washing with sterilized distil water for 3-4 times.

For callus induction MS agar medium supplemented with BAP (2.0 $\left.\mathrm{mg} \mathrm{l}^{-1}\right)$ and 2, 4-D (1.0 $\left.\mathrm{mg} \mathrm{l}^{-1}\right)$ was utilized. Subculturing of obtained callus was done every $21^{\text {st }}$ day on the same medium. The cultures were incubated in the growth room at $28 \pm 2{ }^{\circ} \mathrm{C}, 50 \%$ humidity under dark conditions.

\section{Protein extraction}

Ice-cold extraction buffer consisting of $175 \mathrm{mmol} \mathrm{dm}^{-3}$ Tris/ $\mathrm{HCl}(\mathrm{pH}=8.8), \operatorname{SDS}\left(\gamma=50 \mathrm{~g} \mathrm{dm}^{-3}\right)$, glycerol $(\varphi=$ $15 \%)$ and 2-mercaptoethanol $(\varphi=0.07 \%)$ was used to extract protein from seeds as well as from callus. Five grams of seeds and $5 \mathrm{gm}$ of callus was crushed and dissolved in $3-5 \mathrm{ml}$ of extraction buffer in order to prepare seed extract and callus extract respectively. Cell debris was removed by centrifugation at $500 \mathrm{~g}$ at $4{ }^{\circ} \mathrm{C}$ for 15 minutes. The supernatant was transferred to a new tube and proteins were precipitated by adding four volumes of ice-cold acetone containing trichloroacetic acid $(\varphi=10 \%)$ and 2-mercaptoethanol $(\varphi=0.07 \%)$. Samples were stored at $-20{ }^{\circ} \mathrm{C}$ for at least 1 hour. Pellets were obtained by centrifugation at $15000 \mathrm{~g}$ at $4{ }^{\circ} \mathrm{C}$ for 45 minutes, and washed three times with an ice cold solution of 2mercaptoethanol $(\varphi=0.07 \%)$ in water/acetone $(\varphi=20 \%)$. Pellets were centrifuged at $15000 \mathrm{~g}$ for 15 minutes between washes. Supernatant were discarded, and pellets were dried under air at room temperature [13]. The callus 


\section{Indo Global Journal of Pharmaceutical Sciences, 2015; 5(2): 124-128}

extract was concentrated by using Amicon ${ }^{\circledR}$ Ultra $4 \mathrm{ml}$ centrifugal filter device having pore size of $10 \mathrm{kDa}$.

Protein profiles of seeds, leaves and callus were analyzed through sodium dodecyl sulphate polyacrylamide gel electrophoresis (SDS-PAGE). A 12\% acryl amide gel was used for separation. Staining and destaining was done by using coomassie brilliant blue solution and methanolglacial acetic acid (3:1) solutions respectively.

\section{Trypsin inhibition assay}

The trypsin inhibitory activity was assayed by determining the residual trypsin activity following the method of Kakade et al. [14] with slight modifications, using BApNA as the substrate and bovine trypsin as the standard enzyme. The reaction mixture contained $0.3 \mathrm{ml}$ diluted trypsin inhibitor (callus extract or culture supernatant or culture medium), $0.3 \mathrm{ml}$ trypsin $(2 \mathrm{mg}$ in $40 \mathrm{ml} 0.001 \mathrm{M} \mathrm{HCl}$ ) and $2.1 \mathrm{ml}$ of BApNA (30 mg dissolved in minimum volumes of DMSO and adjusting its final volume to $100 \mathrm{ml}$ with $0.05 \mathrm{M}$ Tris- $\mathrm{HCl}, \mathrm{pH} \mathrm{8.2,}$ containing $0.03 \mathrm{M} \mathrm{CaCl}_{2}$ ) in a final volume of $2.7 \mathrm{ml}$. The final concentration of $\mathrm{BApNA}$ in the reaction mixture was $0.54 \mathrm{mM}$ and the number of trypsin units was 180 . After incubating the mixture at $37{ }^{\circ} \mathrm{C}$ for 15 minutes in a shaking water bath, the reaction was stopped by adding $0.3 \mathrm{ml}$ of $30 \%(\mathrm{~V} / \mathrm{V})$ glacial acetic acid. A blank and a trypsin control were run simultaneously. The absorbance was recorded at $410 \mathrm{~nm}$ against the blank. The amount of substrate hydrolysis by the enzyme was calculated using the molar extinction coefficient of $8800 \mathrm{M}^{-1} \mathrm{~cm}^{-1}$ at 410 nm. Trypsin inhibition activity was calculated by following formula:

$$
\begin{gathered}
\text { (Absorbance of control) }-(\text { Absorbance of sample) } \\
\text { (Absorbance of control) }
\end{gathered}
$$

\section{RESULTS \& DISCUSSION}

Callus formation was achieved from variety of explants which were excised from in-vitro as well as in-vivo growing plant of $M$. dioica. For developing seedling as a regular source of explants, seeds were germinated on three different types of solid supports like water agar medium, moist filter paper and soil. For germination both fresh as well as stored seeds were tested. As shown in Table-1 no germination was obtained from fresh seeds and stored seeds proved better. Maximum germination $(60 \%)$ was achieved from stored seeds on water agar medium. Considerable percentage of germination (40\%) was also obtained from stored seeds which were inoculated on moist filter paper but time taken for germination was more as compared to time taken by seeds which were inoculated on water agar medium.

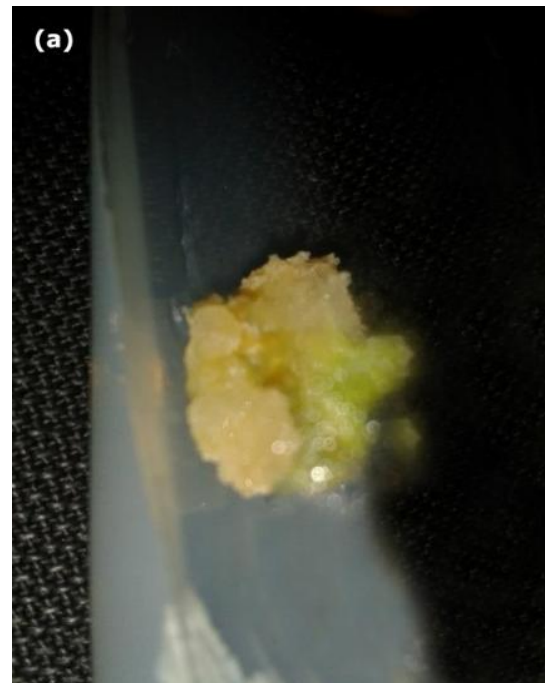

(b)

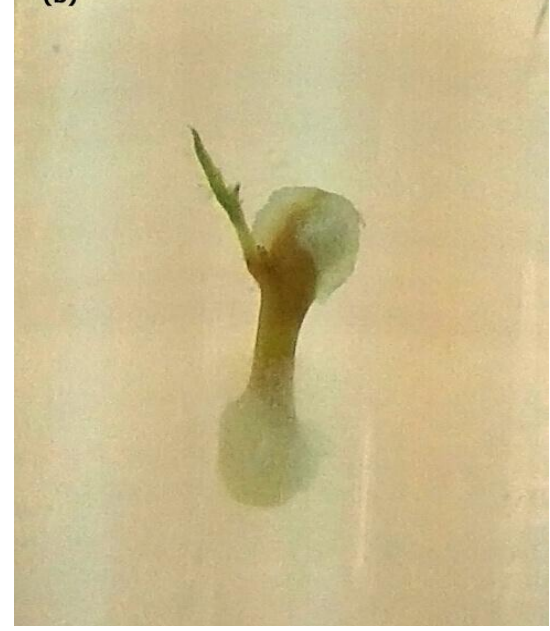

Fig. 1 Callus of $M$. dioica obtained from (a) leaf explants; (b) hypocotyl explants

Calli were obtained from leaves as well as hypocotyls (Fig 1) while cotyledons remained unresponsive. Response of various explants for callus formation is summarised in Table 1. Among all explants, leaves taken from in-vivo as well as in-vitro growing plants gave best response in terms of maximum percentage of callus induction (50-60\%) followed by hypocotyls $(50 \%)$. Intermodal segments were least responsive among all. Efficient plant regeneration via callus organogenesis was attempted by Devendra et al. [15] from leaf. Eighty percent explants gave positive response on MS agar medium containing 2, 4-D and BAP. Micropropagation of 


\section{Indo Global Journal of Pharmaceutical Sciences, 2015; 5(2): 124-128}

M. dioica was also achieved through somatic embryogenesis [16]. Response of various explants (leaf, cotyledon, and root) of $M$. dioica for callus culture establishment was analyzed by Bhosle and Paratkar [17]. They gave a hypothesis that developed callus can be useful in large-scale production of plant secondary metabolites.

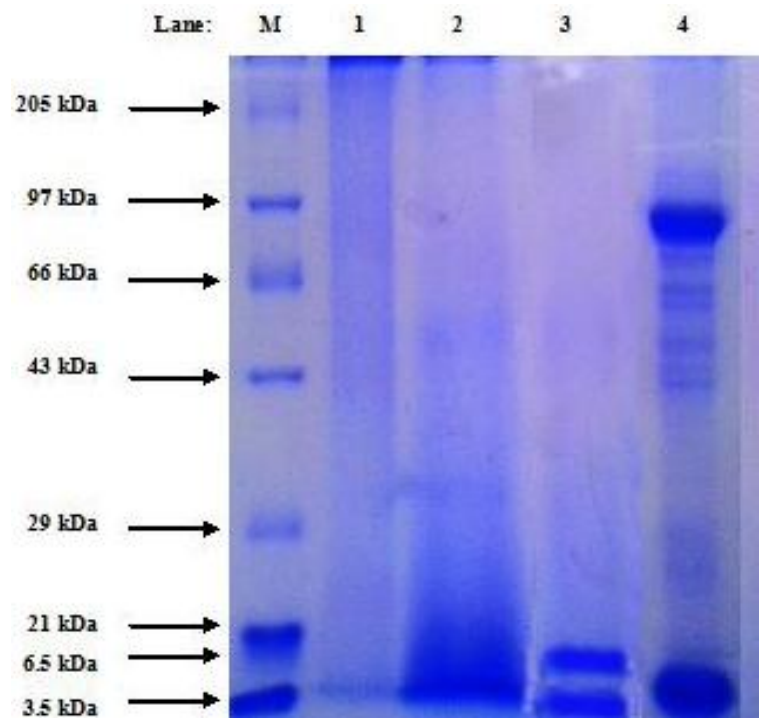

Fig. 2 Analysis of protein profile of $M$. dioica. Lane M: marker; lane 2: leaf extract; lane 3: callus extract; lane 4: media sample; lane 5: seed extract.

Successful establishment of callus cultures was followed by analysis of protein profile of developed callus through SDS-PAGE. Simultaneously protein profile of seed and leaf extracts were also analyzed on the same gel for comparison (Fig 2). Few proteins (two) which are expressed by callus cells are present in seed extract along with several others. The protein concentration is very less and not detectable in leaf extract. The protein bands which are shown in callus extract also detected in media sample on which callus was growing. Presence of similar protein bands in media sample indicates the extracellular nature of these proteins. The approximate molecular weight of detected proteins is $6.5 \mathrm{kD}$ and $3.5 \mathrm{kD}$ (Fig. 2).

The trypsin inhibitory activity was reported in seed extract of $M$. dioica previously in our lab and the molecular weight of the purified inhibitor molecule was found to be around $10 \mathrm{kDa}$ (unpublished). Therefore, trypsin inhibition assay was performed with callus extract and media sample. Callus extract had shown higher level of inhibition of trypsin activity (91\%) as compared to that shown by media sample (54\%). Trypsin inhibitors which were reported in other species of Momordica are of similar molecular weight (below $10 \mathrm{kDa}$ ). Five trypsin inhibitors, having a molecular weight of $5.1 \mathrm{kDa}, 4.8 \mathrm{kDa}$, $4.4 \mathrm{kDa}, 4.1 \mathrm{kDa}$, and $3.9 \mathrm{kDa}$, respectively, were isolated from Momordica cochinchinensis seeds [18]. A trypsin inhibitor consisting of only 62 amino acids was detected, purified and characterized from seeds of M. charantia [19 $\& 20]$. The trypsin inhibitor which was expressed in the seeds of $M$. dioica was also found to be expressed by callus cells.

\begin{tabular}{|l|c|}
\hline \multicolumn{1}{|c|}{ Name of Explant } & Callus Induction (\%) \\
\hline Leaves in-vivo & 60 \\
\hline Leaves in-vitro & 50 \\
\hline Hypocotyl segment & 50 \\
\hline Nodal segment & 40 \\
\hline Internodal segment & 10 \\
\hline Cotyledons & No callus induction \\
\hline
\end{tabular}

Table 1 Response of various explants for callus induction

\section{CONCLUSION}

A significant percent of trypsin inhibition has been reported from Momordica dioica callus cells as well as media samples. The trypsin inhibitory activity of media samples indicate towards extracellular nature of protease inhibitor. Therefore, the work will be extended towards the establishment of suspension cultures for the production of trypsin inhibitor at large scale and its evaluation as bioinsecticide.

\section{ACKNOWLEDGEMENT}

The authors are thankful to Sir Padampat Singhania University, Udaipur for providing laboratory facility as well as financial assistant for present research work.

\section{REFERENCES}

1. Laskowski, M.J.R. and Kato, I. Protein inhibitors of proteinases. Annual Review of Biochemistry, 1980, 49: 685-693.

2. Richardson, M.J. Seed storage proteins: The enzyme inhibitors. In: Methods in Plant Biochemistry, Ed. Academic Press, New York, 1991: 259-305.

3. Lawrence, P.K. and Koundal, K.R. Plant protease inhibitors in control of phytophagous insects. Electronic Journal of Biotechnology, 2002, 5: 1-17.

4. Gatehouse, A.M.R., Norton, E., Davison, G.M., Babbe, S.M., Newell, C.A. and Gatehouse, J.A. Digestive proteolytic activity in larvae of tomato moth, Lacanobia oleracea; effects of plant proteinase inhibitor in-vitro and in-vivo. Journal of insect physiology, 1999, 45: 545-558. 


\section{Indo Global Journal of Pharmaceutical Sciences, 2015; 5(2): 124-128}

5. Lipke, H., Fraenkel, G.S. and Liener, I.E. Effects of soybean inhibitors on growth of Tribolium confusum. Journal of the Science of Food and Agriculture, 1954, 2: 410-415.

6. Hartl, M., Giri, A.P., Kaur, H. and Baldwin, I.T. The multiple functions of plant serine protease inhibitors: defense against herbivores and beyond. Plant Signaling and Behavior, 2011, 6: 1009-1011.

7. Kansal, R., Kumar, M., Kuhar, K., Gupta, R.N., Subrahmanyam, B., Koundal, K.R. and Gupta, V.K. Purification and characterization of trypsin inhibitor from Cicer arietinum L. and its efficacy against Helicoverpa armigera. Brazilian Society of Plant Physiology, 2008, 20: 313-322.

8. Fook, J.M.S.L.L., Macedo, L.L.P., Moura, G.E.D.D., Teixeira, F.M., Oliveira, A.S., Queiroz, A.F.S. and Sales, M.P. A serine proteinase inhibitor isolated from Tamarindus indica seeds and its effects on the release of human neutrophil elastase. Life Sciences, 2005, 76: 2881-2891.

9. Shreedhara, C.S. and Vaidya, V.P. Screening of Momordica dioica for hepatoprotective, antioxidant and antiinflamatory activities. Natural Product Sciences, 2006, 12: 157-161.

10. Bawara, B., Dixit, M., Chauhan, N.S., Dixit, V.K. and Saraf, D.K. Phyto-pharmacology of Momordica dioica Roxb. ex. Willd: A Review. International Journal of Phytomedicine, 2010, 2: 1-9.

11. Rupachandra, S., and Sarada, D.V.L. Anticancer activity of methanol extract of the seeds of Borreria hispida and Momordica dioica. Journal of Pharmacy Research, 2013, 6: $565-568$.

12. Mondal, A., Ghosh, G.P. and Zuberi, M.I. Phylogenetic relationship in different kakrol collections of Bangladesh.
Pakistan Journal of Biological Science, 2006, 9: 15161524.

13. Pavokovic, D., Kriznik, B. and Krsnik-Rasol, M. Evaluation of protein extraction methods for proteomic analysis of non-model recalcitrant plant tissues. Croatica Chemica Acta, 2012, 85: 177-183.

14. Kakade, M.L., Simons, N. and Liener, I.E. The evaluation of natural vs synthetic substrates for measuring the antitrypsin activities of soybean samples. Cereal Chem., 1969, 46: 518-526.

15. Devendra, N.K., Subhash, B. and Seetharam, Y.N. Callus growth and plant regeneration in Momordica dioica (Roxb.) Willd.Cucurbitaceae. American-Eurasian Journal of Sustainable Agriculture, 2009, 3: 743-748.

16. Karim, M.A. and Ahmed, S.U. Somatic embryogenesis and micropropagation in teasle gourd. International Journal of Environmental Science and Development, 2010, 1: 10-14.

17. Bhosle, D.S. and Paratkar, G.T. Callus cultures from Momordica dioica (Roxb.). Journal of Cell and Tissue Research, 2005, 5: 431-434.

18. Ricardo, C.H.W., Fong, W.P. and Ng, T.B. Multiple trypsin inhibitors from Momordica cochinchinensis seeds, the Chinese drug mubiezhi. Peptides, 2004, 25: 163-169.

19. Zeng, F.Y., Qian, R.Q. and Wang, Yu. The amino acid sequence of a trypsin inhibitor from the seeds of Momordica charantia Linn. Cucurbitaceae. FEBS Letters, 1988, 234: 35-38.

20. Kamei, K., Sato, Shin-ichi., Hamato, N., Takano, R., Ohshima, K., Yamamoto, R., Nishino, T., Kato, H., and Hara, S. Effect of P2' site tryptophan and P20' site deletion of Momordica charantia trypsin inhibitor II on inhibition of proteinases. Biochimica et Biophysica Acta (BBA) Protein Structure and Molecular Enzymology, 2000, 1480: 6-12.

Indo Global Journal of Pharmaceutical Sciences( ISSN 22491023 ; CODEN- IGJPAI; NLM ID: 101610675) indexed and abstracted in EMBASE(Elsevier), SCIRUS(Elsevier),CABI, CAB Abstracts, Chemical Abstract Services(CAS), American Chemical Society(ACS), Index Copernicus, EBSCO, DOAJ, Google Scholar and many more. For further details, visit 